valvular incompetence, which is more directly manifested by the evidences of deranged circulation in the lungs or system. These consequently are to be carefully inquired into. The pulse is to be examined chiefly with respect to the indications it gives of ample or insufficient supply of blood, the characteristic modification of the particular valvular affection present being always borne in mind. A comparison also should always be instituted between the strength of the pulse and the force of the heart's impulse. The state of the veins and capillaries will usually be evident, and is of the greatest importance. The eircumstances under which dyspncea is experienced, and the liability of the heart to palpitation, must be inquired into. The information thus obtained, considered in connexion with the existing valvular affection and the degree of dilatation and hypertrophy, will furnish grounds for an opinion as to the patient's actual condition. If the symptoms are not severe, he may long remain in statu quo, or may go downhill very gradually. His future prospects will depend greatly on the influences, favourable or otherwise, which may be in operation-on the state of his blood and tissues, on the pathological character of the valvular lesion, and on the external conditions to which he is exposed. The state of the blood and tissues will affect his immediate prospects : if he is anæmic and ill-nourished, unless these conditions can be remedied, more serious symptoms are imminent. The character of the valvular lesion will have a more remote bearing. The position and mode of life of the subject, whether he is poor, compelled to toil, and exposed to great variations of temperature, or is more happily situated, will obviously have a great influence, both immediate and remote.

When the symptoms become more grave, the degree in which they in themselves threaten life will first claim attention; and it will materially influence the prognosis, according as they are found to be due solely to the heart-disease, or are accounted for by exposure to unfarourable influences. The statical condition of the patient-the valve affected, the degree of dilatation and hypertrophy, the vigour of the heart's action, the state of the pulmonary and general circulation-will now be by far first in importance; the dynamic influences little operative. Taking now two patients, rich and poor, the balance will incline in favour of the poor man. For him, rest, good diet, treatment reversing the conditions which have accelerated the progress of the disease and preaipitated its consequences, may do much. There are no equally powerful remedial measures that we can bring to bear on the patient who has enjoyed, and not abused, the advantages attending the possession of wealth.

When consequences still more serious have arisen -pulmonary œdema, or congestion, or inflammation, or apoplexy, dropsy of the areolar tissue, or of the serous cavities of the abdomen and chest-now, indeed, it matters not greatly for the moment, whether the valvular disease has been rheumatic or degenerative in origin. The first point to be considered is the amount of mischief in the lungs, or the extent of the dropsy, and the rate of development of the one or the other; whether, again, any adequate external cause has cooperated in inducing them; next, the degree of dilatation and hypertrophy which, as indicating the preexisting mechanical difficulty and injurious tendency of the valvular lesion, give now more definite prognostications than the state of the pulse, the embarrassment of the respiration, etc., which are affected by the complications possibly accidental. Under these circumstances, the chances are altogether on the side of the poor man, and almost in proportion to the labour and privation to which he may have been exposed; the complications arising not solely from the state of the heart, but being due also to external influences; whereas, in the case of persons who have previously been sheltered from all injurious agencies, the only assignable cause is in the heart itself; and it is improbable that, having so far failed as to permit of these complications, it will be able to cope with the further difficulty to which they have given rise.

\section{ON THE EVACUANT AND ASTRINGENT PLANS OF TREATING CHOLERA.}

\section{By Haminton Kinglake, M.D., Taunton.}

OF the many diseases that rightly claim the attention of the physician, there is at the present time one which comes home to him with much anxiety, because of the uncertainty in the weapons at his disposal for resisting its invasion; and thus it is that, notwithstanding the light of past experience and the amount of intellectual energy that has been expended on the subject of cholera, we should at this moment be fiercely contesting the question whether the disease be best treated by one class of remedies or its exact opposite-i.e., by evacuants or astringents.

I have no intention, in giving expression to the views which this controversy has suggested, to join or do battle on either side; especially as I think that, in this as in most other contested questions, the truth is divided between the belligerents. All that I propose to do is this : to inquire, in as few words as possible, how far the evacuant and astringent modes of dealing with cholera are consistent with the indications of cure as they present themselves in the course of the disease; and to assign to each class of remedies its proper place in the order of treatment.

Before, however, entering on this inquiry, it is necessary to be armed with a hypothesis, in definition, as it were, of the choleraic poison; and as the one which makes it to consist of organised germs, capable, under favourable conditions, of rapid increase and development, in the fluid on which they may have fastened, is in accord with the main facts in the history of the disease, there is every reason for accepting it until a nearer approach to the actual truth be attained.

From what we already know of the habits, so to speak, of the class of zymotic poisons to which that of cholera belongs, it would appear that the germs representing such poisons find their appropriate food, and therefore the main conditions of their activity and increase, in certain substances educed from organised matter in the course of its decomposition or conversion into more simple or binary compounds; so that, if the blood should happen to become unduly charged with such decomposing substances, either through its importing from without food, air, or water, in a tainted condition, or through any break in that after series of oxidations by which these, along with the effete tissue-products, are ultimately shorn of their organic character, the choleraic germs that might have existed in or subsequently obtained access to the blood so affected, would find there the condition ready at hand for perfecting their development: whereas, if the food, air, and water received into the system be free from taint, and the effete materials of the organism should follow their natural course of oxidation unin. terruptedly, and go straight to the excretory organs to be eliminated, the quantity of decomposing organic matter existing at any one time in the blood would be kept within the limits consistent with 
health ; and in such case these same choleraic germs would have to struggle for life, with the probable result of being starved out and extinguished because of the failure of the means necessary for their continued existence.

Applying these views to the treatment of cholera in its early stage, do we not recognise the occasion for testing the so-called eliminative cure, and find a cogent reason for directing our remedies to the casting out whatever of noxiousness may have been admitted into, or have formed spontaneously in, the blood, not directly by its forced excretion through one channel, but by means of its oxidation, and conversion into those simpler principles, which, when thus elaborated, naturally effect their own elimination in detail at the several organs specialised for that purpose?

Acting on these indications, care should first be taken that the blood be bathed in pure and constantly renewed air, the skin being at the same time prepared by the scrupulous observance of personal cleanliness to take its share along with the lungs in effecting such interunion. This being accomplished, the process of oxidation may be promoted by diluents holding a certain amount of the alkaline carbonates in solution; and, inasmuch as this same process is apt to be interrupted by the presence in the blood of any excess of purely excrementitious material, such as carbonic acid, urea, and the colouring principle of the bile, that may have accumulated therein ! 'rough the failure of the excreting organs wholly to eject it, the skin and kidneys, under such circumstances, might be assisted in the work of elimination by the ordinary remedies suited for effecting such ends; and if the indications should lie specially in this direction, the functions of the liver and intestinal glands may be promoted by small doses of mercury and Dover's powder, followed by a mild aperient, such as castoroil, or by full doses of ipecacuanha, according to the apparent requirements of the individual case. If the diarrhœea should persist, or become serious in its character in spite of these remedies, it will be clear that the choleraic poison has become too potent or has gone too far ahead to be thus overtaken.

Every circumstance would now point to the necessity of adopting the astringent treatment either by acetate of lead or gallic acid, or by sulphuric acid in eombination with chloric ether and aromatics; aiming thereby to save the blood from a further loss of a fluid holding a certain amount of oxygen in solution, and moreover rich in alkaline and other salts, which, there is every reason to believe, are not only essential to the integrity of the blood-corpuscles, and therefore to the performance of their main function as distributors of oxygen, but also tend to quicken the oxidation of such decomposing matters as may be unduly retained in the blood, and in so doing serve also to accomplish the great end in view, that of drying up the source from which the choleraic germs would otherwise draw their supply of food.

In the collapse, or algide stage of the disease, the eliminative treatment, through the instrumentality of oxygen, in one or other of its allotropic forms, might still be persevered in; but, inasmuch as the inspired air now fails to reach the blood because of the pulmonary arteries refusing to pass it on in its vitiated condition to the capillaries of the lung, our endeavour should be to compensate the defect by bringing the blood to the outer air; and this may, to some extent, be done by those means which have been found effectual in promoting the capillary ciroulation in the skin; e.g., friction with turpentine, the hot-air bath, etc.; and if, in addition to these appliances, a trial be made of the injection into the peins of a warm solution of peroxide of hydrogen, giving thereby the spoiled blood a last opportanity of righting itself in the presence of the nascent oxygen that would then be afforded, we shall probably have done all that our imperfect knowledge of the disease would warrant us in attempting.

It will be inferred from what precedes, that the evacuant and astringent modes of treating cholers, though irreconcileable at first sight, may yet each be consistently adopted in its order, with the like object of eliminating from the blood, not the choleraie germs directly, but the organic products by which their life, their increase, and their poison-power, are sustained. It will also be seen that these same organic products may thus, in fact, become the principal factors in the causation of cholera ; and that, as regards the treatment of the disease, those remedies are consequently indicated whose property it is to promote, either directly or indirectly, the oxidation, and thereby the breaking up and ultimate elimination of those matters in the blood which, in passing from an organic to an inorganic", condition, would seem to furnish the special pabulum of the choleraic germ.

\section{Cramsactions of 敏ranthes.}

\author{
Y ORKSHIRE BRANCH.
}

ON A SINGULAR CASE IN WHICH A LARG! AMOUNT OF IODIDE OF POTASSIUM WAS EXCRE'LED IN THE URINE, WITH SUBSEQUENT DISAPPEARANCE OF THE GLUCOSURIA WHICH EXISTED AT THE TIME.

By James Braithwaite, M.D.Lond. (Editor of

Braithwaite's Retrospect of Medicine), Leeds.

$$
\text { [Read July 26th, 1866.] }
$$

ON the 2nd of December, 1864, I was sent for to attend a woman sixty-four years of age, who complained of feverish symptoms, which she attributed to cold. The skin was hot, the pulse quick; and there were mucous râles all over the posterior part of the chest. She had cough, and expectoration, which, however, was not rusty in appearance. Her urine was free both from sugar and albumen. She soon improved, and went down stairs again; but she did not regain her strength beyond a certain point, and during the early part of January she grew weaker ; complained very much of the cold; her skin assumed a dusky shrivelled appearance; her appetite entirely left her; and she was obliged to return to bed. She was quite free from fever, but so feeble that she could hardly remain upright in a chair many minutes at a time. I found that her urine now contained sugar; it was of specific gravity varying from 1022 to 1032 ; it was neutral or slightly alkaline immediately secreted; it contained a mere trace of uric acid. This was the state of the urine on the 18 th, 19th, and 20 th of January. On the 21st, however, the sugar had quite disappeared-there was no trace of it; but, on adding strong nitric acid to the cold urine, a dense and very copious, reddish black, amorphous precipitate was thrown down. This consisted of pure iodine, which was precipitated in a crystalline form by adding nitric acid to the urine, and which gave the characteristic blue reaction with starch.

On the next day, the sugar again reappeared in the urine in large amount; the specific gravity was 1032 ; but there was not a trace of iodine.

On the 23rd, the specific gravity was 1041 ; and there were both iodine and sugar. The following day, there was the sugar alone; nor did any iodine subsequently appear in the fortnight during whieh I 